\title{
Plato on Metaphysical Explanation: Does 'Participating' Mean Nothing?
}

\author{
Christine J. Thomas
}

Department of Philosophy, Dartmouth College

\begin{abstract}
According to Aristotle, Plato's efforts at metaphysical explanation not only fail, they are nonsensical. In particular, Plato's appeals to Forms as metaphysically explanatory of the sensibles that participate in them is "empty talk" since "participating" means nothing" (Met. 992a28-9). I defend Plato against Aristotle's charge by identifying a particular, substantive model of metaphysical predication as the favored model of Plato's late ontology. The model posits two basic metaphysical predication relations: self-predication and participation. In order to understand the participation relation, it is important first to understand how Plato's Forms are selfpredicative paradigms. According to the favored model, Forms are self-predicative paradigms insofar as they are ideal, abstract encoders of structural essences. Sensibles participate in Forms by exemplifying the structures encoded in the Forms. Given plausible conditions on metaphysical explanation, Plato's appeals to abstract Forms as metaphysically explanatory of sensibles is a reasonable competitor for Aristotle's appeals to natural, substantial forms. At the very least, Plato's appeals to a participation relation are not empty.
\end{abstract}

Keywords: participation, Plato, explanation, predication, paradigm

\section{Introduction}

Aristotle is no fan of Plato's attempts at metaphysical explanation. Plato's appeals to unchanging, intelligible Forms as somehow metaphysically explanatory of changing sensibles comes under considerable scrutiny. ${ }^{1}$ According to Aristotle, "above all one can raise the difficulty about what in the world it is that Forms contribute to (sumballetai) sensibles" (Met. I.9 991a8-10). Aristotle's answer- "nothing." Aristotle assumes that Forms are not in sensibles

Corresponding author's address: Christine J. Thomas, HB 6035, Dartmouth College, Hanover, NH 03755, USA. Email: christine.j.thomas@dartmouth.edu.

${ }^{1}$ For helpful discussion of Aristotle's criticisms of Plato, see (Fine 1993). For focused discussion of texts cited here (from Metaphysics Alpha) see the articles collected in (Steel and Primavesi 2012). 
and that they, therefore, cannot play any substantive causal, epistemological or metaphysical role with respect to sensibles (991a11-14). Moreover, he claims, "to say that Forms are models (paradeigmata) and that other things participate (metechein) in them is empty talk and to use poetic metaphors" (991a20-2). For "participating', as we said before, means nothing" (992a289). Elsewhere Aristotle recommends that we "say goodbye to the Forms. They are mere trilling. Even if they exist, they add nothing to explanation" (APO. I.22 83a32-4).

Aristotle claims that Plato's Forms are separate from sensibles and not in them. ${ }^{2}$ So, even if Platonic Forms exist, either the participation relation does not in fact obtain or it does obtain, but when this occurs, it is of no significance. Either way, participation cannot serve as a metaphysically explanatory relation. On Aristotle's view, explanatory principles of sensibles are causes and substances of sensibles; and the primary cause and substance of a sensible must be in the sensible. Forms are not in sensibles. So Forms cannot be the primary causes and substances of sensibles. They cannot play the role in metaphysical explanation that Plato assigns to them. Whatever characterizations Plato might offer of the participation relation, separation is a problem. Call this The Separation Charge.

Sometimes, however, Aristotle's complaints express his frustration at not understanding what participation in a paradigmatic Form could be. More strongly, he suggests that there is nothing there to understand. At best, talk of paradigms and participation is mere metaphor. At worst it is empty talk, idle noise-making. Call this second complaint The Emptiness Charge. Aristotle's two charges are related, of course. Separate Forms are not in sensibles and so, on his view, they bear no substantive, explanatory relation to sensibles. Talk of paradigms and participation, then, whatever it might amount to, tracks nothing of interest to philosophers (and perhaps tracks nothing at all).

The Separation Charge is at the heart of Aristotle's criticisms. But in order to assess that charge fully, we must strive to understand how Plato conceives of "paradigms" and "participation". In order to determine whether or not

${ }^{2}$ I assume here that Aristotle's concerns arise primarily from his view that Forms are separate from sensibles. Forms are separate from sensibles in that they are themselves by themselves, they are auto kath auto beings. How best to understand the separation relation is a matter of rich scholarly dispute. I understand the separation of Forms to have both epistemological and ontological import. Forms can be defined independently of sensibles; and Forms can both exist uninstantiated and also be the sorts of beings they are independently of sensibles. Aristotle adds that, even assuming sensibles participate in Forms, those Forms are not in sensibles. For discussion, see (Devereux 1994) and (Fine 1984). The separation relation plays an important role in other metaphysical relations, namely relations of ontological priority and ontological dependence. See section 5 of the paper for brief discussion. 
the separation of Forms from sensibles prevents participation from occurring or from serving as a genuinely explanatory relation, we must develop, insofar as possible, a working model of Plato's participation relation. For the purposes of this paper, then, I will focus on The Emptiness Charge. I will suggest that, over the course of a number of dialogues, Plato's talk of Forms as "paradigms" and sensibles as "participating" in them is ambiguous. Plato identifies at least two different roles a paradigm might play and, as a result, there are few different relations that might be characterized by his terminology of "participation". If 'participating' does not initially specify a single relation, then perhaps Aristotle is right that the term is poetical. Even so, it is poetical in acting as metaphorical shorthand for a family of relations or for a variety of particular, nonmetaphorical relations. Those relations are significant and (potentially) explanatory, and appealing to them is not mere trilling.

Ultimately, however, after expanding and clarifying his metaphysical commitments, Plato settles on a single role for Forms to fill as paradigms and a single, substantive participation relation. ${ }^{3}$ The proposal Plato eventually favors, I will argue, is one according to which Forms are paradigms insofar as they encode abstract structures; and sensibles participate in Forms insofar as sensibles physically exemplify the structures encoded in Forms. 'Participating' is not an empty term; it means something. The Emptiness Charge does not stick.

If 'participation' talk is not idle noisemaking, what does such talk mean? How does Plato conceive of the participation relation such that it is (purportedly) explanatory? In order to address such questions and respond to The Emptiness Charge, it will help to begin with an accounting of Plato's ontology of basic beings and basic metaphysical predication relations. If we are to understand how Forms are predicated of sensibles when participation occurs (e.g. how Beauty is predicated of Helen when she participates in Beauty), we must also understand Plato's commitment to the view that Forms are predicated of themselves (e.g. Beauty is predicated of Beauty itself). For Plato, the participation of sensibles in Forms presupposes the self-predication of Forms. In order for the Form of Beauty to explain how something else is beautiful (e.g. Helen), The Form of Beauty must itself, somehow, be beautiful.

3 The interpretation of Plato defended in this paper allows that Plato's metaphysics develops in some important respects across the course of his dialogues. What is perhaps equally important to the interpretation, however, is that many aspects of Plato's metaphysics remain the same across the dialogues. Although the terms 'paradigm' and 'participation' are initially ambiguous, the ambiguity is resolved in favor of a version of one of Plato's initial proposals. In other words, the basic elements of Plato's mature metaphysics are contained already in his earliest ontology. 
There are a variety of interpretative options for understanding self-predication and participation. It proves helpful to group various approaches into two families: Plural Predication approaches and Assimilation approaches. According to Plural Predication approaches, the self-predication relation differs from the participation relation. A common way of characterizing the different predication relations is to say that a Form is $\mathrm{F}$ or is what it is to be $\mathrm{F}$, while a sensible has $\mathrm{F}^{4}$ On such approaches Forms are paradigms as definable essences, and sensibles are dependent on Forms in at least the following sense: no sensible can instantiate $\mathrm{F}$ unless something-a Form-is what it is to be F. Assimilation approaches, on the other hand, posit a single predication relation for cases of self-predication and participation alike. The Form of Beauty and a beautiful sensible have Beauty predicated of them in the same way: both instantiate Beauty. On such approaches Forms are self-exemplifying instances and sensibles participate in Forms by standing in relations of resemblance to them. ${ }^{5}$ On Assimilation approaches, Forms are paradigms by being perfect exemplars of properties (or kinds), and sensibles participate in Forms by deficiently resembling them, by being imperfect copies. ${ }^{6}$

Aristotle, especially in his Emptiness Charge, tends to attribute some version or other of an Assimilation approach to Plato. Aristotle's attribution is not altogether unfair since Plato sometimes seems attracted to such an approach. But Plato is, in the same dialogues, also attracted to a Plural Predication approach. And when he finally comes explicitly to scrutinize and to develop his metaphysics of self-predication and participation, Plato rejects Assimilation models as deeply problematic and opts instead to endorse only a Plural Predication model. And while, pace Aristotle, both models make substantive proposals about what the participation relation might be, Plato's preferred model is not susceptible to some of the difficulties Aristotle raises for Assimilation approaches. ${ }^{7}$

4 There are a variety of importantly different plural predication approaches. See, for example, (Allen 1960), (Code 1983), (Nehamas 1979), (Silverman 2002), and (Vlastos 1969a).

5 Commentators, besides Aristotle, who assign this approach to Plato include Devereux (2003) and Malcolm (1991).

${ }^{6}$ There are differences, of course, between symmetric relations of similarity and the asymmetric relation that a copy stands in to its model. Plato and Aristotle both seem to conflate the symmetric and asymmetric relations at some points in their discussions of participation as resemblance.

7 Even given a Plural Predication approach, whether or not The Separation Charge stands is a different, albeit related matter. See my "Plato on Separation and Participation", unpublished manuscript, for discussion. Addressing that charge requires defense of the view that sensibles and separate Forms can indeed enter into the participation relation as Plato's Plural Predication model characterizes it. It also requires sorting out the relations of separation and ontological priority in more detail than I take in section 5 of this paper. 
In fact, Plato's efforts at metaphysical explanation are mirrored by parallel efforts in Aristotle. Both philosophers begin with ontologies that posit basic substances and basic predication relations. For Plato, Forms are the basic beings, and self-predication and participation are the basic metaphysical relations. For Aristotle, in the Categories, living organisms, like Socrates or Secretariat, are primary substances; and everything else is predicated of beings like them via one of two possible predication relations. Every other kind of being is either said of primary substances or present in primary substances. Human is predicated essentially of Socrates by being said of him. Musical is predicated accidentally of Socrates by being present in him.

But neither Plato nor Aristotle stop with an initial introduction of an ontology of basic beings and basic predication relations. Both eventually turn their attention to the metaphysics of the most basic beings in those ontologies-Forms for Plato and primary substances for Aristotle. As their metaphysics develop, both philosophers discover that there is more to be said about the internal, predicational structure of their basic beings than their original ontologies revealed. As it turns out, Forms have internal structure and stand in both types of Plato's basic predication relations. The Form of Courage is what it is to be courageous and it has the property of being eternal. Moreover, as a being, Courage is also one and self-identical. In his later dialogues, Plato recognizes and distinguishes various types of basic predication relations into which Forms enter and decides that even the unity and complexity of Forms requires metaphysical explanation. ${ }^{8}$ For Aristotle, the analysis of change in the natural world reveals that living organisms are actually complex compounds of form and matter. Socrates, it turns out, is a hylomorphic compound; he is ontologically dependent on his form and matter.

Ultimately, even with their mature, developed metaphysics in hand, both philosophers are left striving to understand how their most fundamental, ontological beings and principles are related to the sensible subjects they purportedly unify, organize and explain. For Aristotle, substantial forms in hylomorphic compounds actualize potentialities in matter and thereby cause particular types of sensible compounds with particular types of capacities to come into being and to persist through change. To be sure, Aristotle makes more progress than Plato makes in developing a metaphysics that illustrates how the basic beings in the ontology-substantial forms-are metaphysically explanatory of the unity, organization and persistence of sensible particulars. Aristotle makes more progress in understanding his ver-

${ }^{8}$ While the Republic and Timaeus expand on the Phaedo's basic metaphysical commitments, the dialogues in which the metaphysics of the most basic beings is considered in greatest detail include especially the Parmenides, Sophist and Philebus. 
sion of formal causation. Even so, for Plato too, sensibles are organized and unified in virtue of the relations they stand in to more basic, unifying and structuring beings and principles. For Plato, those basic structuring principles are Forms. ${ }^{9}$ In what follows, I hope to shed some light on Plato's views of participation and metaphysical explanation by identifying some important stages in the development of his ontology.

\section{Plato's Ontology}

In the Phaedo, Plato divides what there is into two primary categories, the changing perceptibles and the unchanging, imperceptible beings $(78 \mathrm{cl}-$ 79a3). Beings are incomposite, uniform, everlasting Forms. They are intelligible objects that exist themselves by themselves, unmixed with sensibles. Forms are essences or substances (ousiai). To inquire into Forms is to inquire into what things are as they are in themselves; it is to inquire into such things as Justice itself and Beauty itself (65d12-66a3). The many beautiful human beings or cloaks or horses, on the other hand, are perceptible and composite. They come into existence, go out of existence and constantly change while in existence. They inhabit the realm of becoming.

With the most basic, metaphysical categories in place, ${ }^{10}$ Plato proposes that sensibles are dependent on Forms. Sensibles are called after (i.e. share the same name as) Forms and come to be the way they are in virtue of participating in Forms. Poppy is courageous, for example, because she participates in Courage itself. Michelangelo's David is beautiful because it participates in Beauty itself. Plato puts the point as follows:

If anything else is beautiful besides Beauty itself, it is beautiful due to nothing else than because it participates (metechei) in Beauty itself. And I speak in the same way about everything else. Do you agree with this sort of explanation (aitia)? (Phd. 100c4-7)

We can detect two important commitments in this passage. First, the Form of Beauty itself is beautiful. Second, if anything else is beautiful, it is so by coming to participate in the Form. Plato offers this two-fold proposal as an abbreviated account of the role that Forms play in aitia, in explanations of sensibles coming to be and coming to have the features they have. First,

9 I retain the terminology of 'Forms' to refer to the foundational items in Plato's ontology across developments in the middle and late dialogues. As I see it, the main features and functional roles played by Plato's basic beings remain sufficiently constant across developments and dialogues that, even while certain features and characterizations of those beings are surrendered or revised, it is reasonable to retain the label of 'Forms' for those beings.

${ }^{10}$ Souls exist too and, according to Plato, are more akin to Forms than to sensibles. Although individual souls apparently move and change, they are imperceptible and everlasting. 
Forms are self-predicative. The Form of F is itself F. Second, if any sensibles are F, they are F in virtue of participating in self-predicating Forms.

In appealing to Forms as aitia, Plato develops his approach to metaphysical explanation in light of his ontology. Consider Robert Bolton's remarks: ${ }^{11}$

When Plato, in the Phaedo, explains why some sensible thing comes to be, for instance, hot by saying that this is for no other reason than because it comes to participate in the Hot itself $(105 \mathrm{~b}-\mathrm{c})$, what he means to be doing is to show us how to understand this event metaphysically: that is by reference to the ontologically fundamental types of entities that figure in this event-namely, Forms and sensiblesand by reference to the ontologically fundamental relation that joins these types of entities-namely participation. (Bolton 1998, 94)

In Plato's ontology, there are sensibles and Forms, and a fundamental relation of participation that somehow links them.

But there is also the fundamental relation of self-predication: the Form of $\mathrm{F}$ is itself $\mathrm{F}^{12}$ The Form of Beauty is itself beautiful. The Form's beauty is not, however, explained by appeal to a participation relation. Instead, the Form of Beauty is beautiful in virtue of being what it is to be beautiful. ${ }^{13}$ The self-predication of Forms-however we ultimately understand its detailsis more fundamental to Plato's ontology than the relation of participation. ${ }^{14}$ The relation of participation presupposes the self-predication of Forms.

Plato, by his own admission, does not give his audience much to go on in understanding the basic predication relations:

Nothing else makes something beautiful other than the presence or communion of that Beauty itself (or whatever sort and nature the relation we mentioned may be; for I will not affirm the nature of the

${ }^{11}$ For useful discussions that develop differently but that also focus on metaphysical (or logico-metaphysical) explanation in Plato's Phaedo, see also (Vlastos 1969b) and (Sharma 2009).

${ }^{12}$ At Phaedo 102aff, various Forms are described as self-predicative and not admitting their opposites so as to remain what they are. Tallness itself is tall, for example, and does not admit smallness. Texts in which self-predication claims occur include: Protagoras $330 \mathrm{off}$. (the just is just, and the pious is pious), and Hippias Major 292e6-7 (the beautiful is beautiful).

${ }^{13}$ Allan Silverman finds the metaphysics of the Phaedo especially noteworthy: "This is a watershed moment: it is the first time a metaphysician proposes an account utilizing two primitive ontological relations. [...] The fundamental difference between them, in my opinion, is that Participation is a characterizing relation whereas Being is not. By characterizing I mean that the subject, in virtue of participating in a Form, comes to have a property in an ordinary, naïve sense. [...] Being is a primitive ontological relation designed exclusively to capture the special tie between that which possesses an essence and the essence possessed" (Silverman 2002, 14-15).

${ }^{14}$ For discussion and defense of the view that self-predication is the first and most basic predication relation, see (Nehamas 1979). 
relationship, but only that all beautiful things are beautiful by Beauty itself) (Phd. 1ood3-8).

Details are not forthcoming in the Phaedo. There are, nevertheless, defensible ways of piecing together Plato's remarks and commitments to identify two broadly conceived models of metaphysical predication in the middle dialogues. As one might expect, each model presupposes a distinct view of self-predication.

How commentators understand the self-predication of Forms often turns on the role they assign to Forms as paradigms. Self-predication applies to the most basic beings from very early on in the Platonic corpus; and the basic beings are identified as paradigms very early on too. Socrates seeks definitions of beings in the Socratic dialogues. When, for example, Socrates asks Euthyphro for instruction about piety, he asks Euthyphyro to teach him about "that form itself by which all the pious things are pious [...] so that looking to it and using it as a paradigm (paradeigmati), whatever is such as it is, I shall say is pious and whatever is not such, I shall say is not" (Euthyp. 6d9-e7). Socrates requests that Euthyphro provide a definitional account of the nature or essence of piety so that, in light of the definition, Socrates can identify and classify particular actions or action types as pious or impious. Piety is a paradigm, in this context, insofar as it is a definable, knowable essence that provides a universal standard against which to measure individual cases to test whether or not they are instances that meet the definition. If they satisfy the definition, they are such as piety is; if they do not, they are not.

The explanatory role assigned to such paradigms follows from their being objects of (real) definitions. The explanation of the fact that the liquid in the glass is water, for example, is the fact that the liquid in the glass is $\mathrm{H}_{2} \mathrm{O}$. The liquid in the glass satisfies the definition of 'water' and its satisfying the definition explains why it counts as an instance of water. Paradigms act as metaphysically explanatory factors, on this approach, insofar as they are definable essences that figure in explanatory accounts. ${ }^{15}$ Paradigms explain instances by classifying or categorizing them.

A second way in which basic beings are regarded as paradigms is evident in other contexts, where the basic beings appear as perfect exemplars. At Symposium 211aff., for example, Beauty itself is the most beautiful thing of all, more beautiful than beautiful bodies or beautiful learning; and unlike beautiful sensibles, Beauty itself is always pure and unmixed, it is beautiful and never not beautiful. ${ }^{16}$ Here, the comparison of paradigmatic Beauty

${ }^{15}$ See (Ferejohn 2013) for discussion.

${ }^{16}$ See also Hp. Ma. 289d. 
with nonparadigmatic beauty suggests that the perfectly beautiful Form is simply the purest and most beautiful among the various beautiful things. The assumption that Forms are exemplars, despite some obvious absurd results (e.g. the Form of Large would be the supremely large thing), has some considerations in its favor. For one, it connects well with some of Plato's commitments regarding aitia. Plato, like many of his predecessors (and successors), assumes that the cause or producer of F, must itself be F. According to Socrates, for example, "if piety itself is not pious it is difficult to see how anything else can be pious" (Prt. 330c5). Plato, in the Phaedo, argues that Forms, as opposed to sensibles, satisfy the constraints on adequate aitia. Unlike sensible Fs, the Form of $F$ is itself $F$ and never not-F. The approach to paradigmatism as self-exemplification emphasizes the idea that Forms as aitia must have the very same properties they somehow cause or explain in the sensibles that participate in them.

Distinguishing two different ways in which Forms serve as paradigmsas definable essences or as perfect exemplars-makes it easier to understand how different approaches to the participation relation arise for Plato. ${ }^{17}$ According to Plural Predication approaches, being predications relate Forms to their essences or natures, while having predications relate subjects to the properties they have. ${ }^{18}$ In this way the very same property is predicated of both sensibles and Forms, but the property is predicated by means of distinct predication relations. What renders sensibles dependent and deficient with respect to Forms, then, is not located in the degree of purity of the property, but in the way the property is predicated. A sensible's having $\mathrm{F}$ is dependent on a Forms's being F. A sensible gets classified as an $\mathrm{F}$ when it satisfies the definition of F itself; but sensibles satisfy the definition of $F$ itself only if there is an essence of $\mathrm{F}$ itself to be defined.

A second approach to understanding self-predication and participation,

${ }^{17}$ In my view, Plato is attracted, for different reasons, to both types of paradigmatism until the Parmenides, where he criticizes and rejects the view that Forms are self-exemplifying. Malcolm (1991) defends a similar position, but attributes a more pointed confusion to Plato. According to him, "the same entity is illegitimately taken to be both a universal and also its (paradigm) instance, as something common to the particulars and as something in common with them" (Malcolm 1991, 52). Because I regard Plato's commitment to Forms as definable essences as his favored version of paradigmatism throughout the corpus, I take the self-exemplification of Forms to be less central to the middle dialogues than Malcolm. See (Prior 1983) for defense of the view that, at no point, does Plato take his Forms to be exemplars. On Prior's view, Plato's Forms are only ever paradigms as abstract patterns, not exemplars. I argue in sections 3 and 4 of the paper, that Plato's mature Plural Predication approach most explicitly casts Forms as something akin to abstract patterns.

${ }^{18}$ For representatives of this type of approach to the Phaedo, see (Nehamas 1979), (Silverman 2002) and (Stough 1979). Distinct versions of the Plural Predication approach in the Parmenides will be considered in section 3 . 
the Assimilation approach, does not deny that the Form of $\mathrm{F}$ is what it is to be F. ${ }^{19}$ But it does not identify this fact about a Form as constituting paradigmatism or self-predication for a Form. Instead Forms are paradigms by selfexemplifying, by being perfect instances of the properties they exemplify. And sensibles participate in Forms by resembling them. If Forms and the sensibles that participate in them have the very same property predicated of them in the very same way, then it also makes sense to describe the participation relation as a relation of similarity or imitation. The properties instantiated in sensibles are like the properties instantiated by Forms, but only approximately so. Sensibles are deficient copies of Forms.

Aristotle complains that Plato's participation relation is a mysterious affair, "what this participation or imitation (mimesin) of the Forms could be, they left an open question" (Met. 987b13-14). Not only is there an absence of precision in the Phaedo, insofar as Forms are cast as both definable essences and also self-exemplifying aitia across the middle dialogues, Plato appears drawn to both Plural Predication and Assimilation approaches. When he wishes to draw category distinctions between sensibles and Forms, the plurality of predication relations are salient. The Form of $\mathrm{F}$ is what it is to be $\mathrm{F}$ and a stable, definable universal; sensibles merely have $\mathrm{F}$ (and not $\mathrm{F}$ ) and are constantly changing. When Plato wishes to appeal to Forms as aitia, Forms have the properties they cause sensibles to have and participation is treated as some kind of assimilation relation.

Is this careless inconsistency on Plato's part? Unclarity? Experimentation? It is difficult to say. But a plausible case can be made that Plato's interest in both approaches is manifest at different points in the Phaedo, Symposium and Republic. In all three dialogues, Plato treats the very same beings as, on the one hand, universal, definable essences that serve as objects of knowledge, and, on the other hand, as perfect exemplars that are causally responsible for the features of the sensibles that resemble them. Aristotle is critical of Plato's dual interest. He accuses Plato of treating Forms as if they have the natures of both universals and particulars at once, as if Forms are both suches and thises. ${ }^{20}$ Insofar as Plato is attracted to both types of paradigmatism, the middle dialogues are subject to Aristotle's criticism. But Plato has more to say about Forms than what appears in the middle dialogues. To learn more about self-predication and participation, we need to look elsewhere. $^{21}$

${ }^{19}$ For representatives of this approach (at least for the middle dialogues), see (Devereux 1994, 2003), and (Malcolm 1991).

${ }^{20}$ See Met. 1038a34-1039a2 and 1086a33-b27; Soph. El. 178b36-179a1o. See (Shields 2008) for an interesting discussion of Aristotle's charge.

${ }^{21}$ Were we interested to investigate the metaphysics of the Phaedo in greater detail, we would need to consider the role of Form characters or immanent characters (e.g. the tallness-in- 


\section{Paradigms and Predication}

Plato does not stop with his initial introduction of an ontology of Forms, sensibles and predication relations. In some of his later dialogues, he eventually turns his attention to a critical investigation of his fundamental metaphysical commitments. In the process, he decides that there is much more to understand about the internal and external predicational structure of the Forms. ${ }^{22}$ For one thing, according to the Parmenides (155e-158d) and Sophist (254-256), Forms can participate in one another. Each Form is one, selfidentical and different from every other Form in virtue of participating in Oneness, Sameness and Difference. Presumably a Form like Largeness itself, for example, is both large and intelligible. It is large in virtue of being what Largeness is; it is intelligible in virtue of participating in the Form of Intelligibility. Once it is clear that Forms can participate in one another, the self-predication of Forms needs to be distinguished from the participation relations Forms stand in with respect to one another.

In addition, the Parmenides reveals that, if Plato is to avoid problematic results for his metaphysics, he will need to reject Assimilation approaches to paradigmatism and participation. In fact, the two defining elements of Assimilation approaches determine the two regress challenges Plato develops in the Parmenides. In the first instance, the assumption that the Form of $\mathrm{F}$ is self-exemplifying, that $\mathrm{F}$ itself and sensible Fs have the very same property (along with other assumptions) generates an infinite regress of Forms of F. In the second instance, the identification of participation with a resemblance or imitation relation is the source of an infinite regress. The Parmenides illustrates that Assimilation approaches permit the generation of unacceptable regresses and should be rejected. Once Assimilation approaches are rejected, Plato is liberated from the view that Forms are paradigms as perfect exemplars and can surrender the idea that participating in a Form is a matter of

Simmias). Both Assimilation and Plural Predication models can incorporate immanent characters as (controversial) additions to the ontology, so I do not see that admitting them into the ontology inclines readers to prefer one model over the other as the best fit for the Phaedo. The status of immanent characters is very difficult to discern. For defense of the view that immanent characters are included in the ontology in the Phaedo, see (Devereux 1994) and (Silverman 2002). For the view that Forms themselves are immanent in the Phaedo, see (Fine 1986).

${ }^{22}$ The Parmenides is a challenging dialogue and there is a lot to say about Plato's ambitious efforts. I will touch on only a few of Plato's insights in the Parmenides. For some diverging opinions about how best to understand the developments in Plato's later metaphysics, see (Gill 2012), (McCabe 1994), (Meinwald 1991), (Sayre 1983), and (Silverman 2002). According to Meinwald, the dialectical exercise of the Parmenides is nothing less than "designed to display all the results concerning the structural relations of the basic explanatory entities and also their role in the world" (Meinwald 1991, 26). 
deficiently resembling it.

Consider the first regress (Parm. 132a1-b2). ${ }^{23}$ If the Form of Largeness is large in the same way that large sensibles are (only approximately) large, then large sensibles and Largeness itself can be gathered together into a collection, each member of which has the same property in the same way. In order to explain the common feature had by the many items in the collection, a single Form to cover the many instances of largeness is required. Assuming the Form of Largeness cannot explain its own largeness, a second Form of Largeness is required. ${ }^{24}$ But it too will have the property of being large that it explains in its participants. Another collection including the large sensibles, the first Form of Largeness and the second Form of Largeness can be formed. A third Form of Largeness will be required to explain all of the instances of largeness in this new collection. And so on. An infinite regress of Forms of Largeness looms.

In the second case, the assimilation relation itself is responsible for a regress. The Assimilation approach Plato targets here is one suggested by various passages in the Republic (e.g. 50ob-501b, 509d-520c, 596aff.) where Plato depicts Forms as perfect exemplars and sensibles as images, imitations and copies. It is also the approach Aristotle alludes to when formulating The Emptiness Charge. Plato reconstructs the position he then goes on to criticize as follows: ${ }^{25}$

The most likely view is that Forms are established in nature as par-

${ }^{23}$ The form of the first regress has come to be called "The Third Man Argument" after Aristotle's similar version of a regress argument. For just a sample of the abundant literature on the topic, see (Meinwald 1991, 1992), (Pelletier and Zalta 2000), (Peterson 1996), and (Vlastos 1969a).

${ }^{24}$ The assumption that the Form of Largeness cannot explain its own largeness is difficult to reject on an Assimilation approach. If the many sensibles that are $\mathrm{F}$ require explanation in terms of something other than themselves, and if the Form of $\mathrm{F}$ is $\mathrm{F}$ in the very same way that the sensibles are F, it is difficult to see how the Form could fail to require explanation in terms of something other than itself or other than the collection of which it is a member.

${ }^{25}$ Waterlow (1982) interprets this passage from the Parmenides as playing a dual role. First, the passage recalls the self-exemplifying paradigms that are imitated by sensibles in the Republic. Second, the passage contains in itself precisely the tools to reject the Republic's model of paradigmatism and participation and replace it with the later Timaean model. In the Timaeus, Forms are paradigms as models and sensibles are literally modeled after them by the agency of a divine craftsman. In the Timaeus, "being modeled after" is explicitly an asymmetric relation that requires an agent. While I appreciate Waterlow's efforts to accommodate both a revision of the middle period metaphysics in light of the Parmenides' criticisms and an account of the revisions that is consistent with the paradigmatism of the later Timaeus, I do not think her interpretation takes the revisions of the metaphysics quite far enough in reimagining paradigmatism. My own view of how best to understand the metaphysics of Forms in the Parmenides and Timaeus will become clearer over the course of the next two sections of the paper. 
adigms, and that the other things resemble these and are likenesses of them; and the participation of these things in Forms is nothing other than their being modeled after them. (Parm. 132d1-4)

The Assimilation approach regards participation as resemblance between sensibles and Forms. But something must explain how it is that sensibles and Forms are alike, namely their participation in the Form of Likeness itself. But, on this approach, participation just is likeness. So, in order to participate in Likeness, Forms and sensibles must be like Likeness itself. But, again, something must explain how it is that sensibles, Forms and the Form of Likeness itself are all alike. A second Form of Likeness is required. But accounting for participation in the second Form of Likeness will require yet another Form of Likeness. The initial appeal to similarity relations generates an infinite regress of similarity relations, and an infinity of Forms of Likeness to explain them. ${ }^{26}$

Assimilation approaches posit a single type of predication relation, the relation of having. The property beauty is had in the same way by both Forms and sensibles, even though the sensibles' instances only approximate the perfection and purity of the Formal instance. The regress arguments of the Parmenides illustrate that both assumptions need to be rejected. A plurality of predication relations is required and participation is something other than similarity. According to Plato, "other things do not get a share (metalambanei) of Forms by likeness; we must seek some other means by which they get a share" (Parm. 133a5-6). Once Plato diagnoses the difficulties with Assimilation approaches and surrenders them, he is free to pursue and develop a version of a Plural Predication approach as a better option. And that is exactly what he does.

In the Parmenides (and Sophist), Plato begins to distinguish more explicitly and systematically between two types of metaphysical predication (Parm. 136a5-b1, 16ob2-4, 166c2-5; Soph. 256a12-b2). He develops terminology to mark out the two types of predications: pros ta alla (relative to other things) and pros heauto (relative to itself). ${ }^{27}$ 'Poppy is beautiful' and 'Poppy is human' express pros ta alla predications. Poppy is beautiful and Poppy is human relative to other things, namely the Forms of Beauty and

${ }^{26}$ For discussion of the Likeness Regress, see (Gill 2012, 39-41), (McCabe 1994, 87-90), and (Schofield 1996).

${ }^{27}$ For defense of the view that Plato distinguishes multiple, basic predication relations in the Parmenides, see (Meinwald 1991, 1992), (Pelletier and Zalta 2000), (Peterson 1996) and (Silverman 2002). Frede $(1967,1992)$ distinguishes between kath' hauto (in itself) predication and pros allo (in relation to something else) predication in the Sophist. The distinctions in the two dialogues do not map exactly onto one another, but they illustrate that Plato is attracted to multiple types of predication. 
Humanity. 'The Form of Beauty is beautiful' and 'Triangularity itself is 3sided' express pros heauto predications. Beauty is beautiful relative to itself and Triangularity is 3 -sided relative to itself.

At a minimum, the Parmenides begins more systematically to distinguish between the being and having relations recognized in the middle dialogues. The Form of F is F pros heauto insofar as The Form of F is what it is to be $\mathrm{F}$ in itself. Sensibles are $\mathrm{F}$ pros ta alla insofar as sensibles have $\mathrm{F}$ in virtue of their relations to something else, namely $\mathrm{F}$ itself. But a virtue of the Parmenides' two predication relations is that they introduce more flexibility than that. For example, 'The Form of Largeness is intelligible' is a pros ta alla predication between a Form and another Form. Forms can stand as subjects in predication relations other than relations of being. Moreover, Forms can stand in pros heauto relations that extend beyond merely the tie that binds a Form directly to its essence or real definition. For example, 'Justice is a virtue' is a pros heauto predication, since the predication holds in virtue of what Justice is in itself. Still, 'virtue' does not figure in the real definition of Justice if Justice is defined as it is in the Republic (as each part of a complex whole doing its own work without interfering with the other parts). ${ }^{28}$ Instead, 'Justice is a virtue' is a pros heauto predication insofar as it is appropriately related to a real definitional pros heauto predication.

That Plato is attracted to Plural Predication is clear. But simply attributing to him a preference for Plural Predication over Assimilation is insufficient. For Plato's revised approach to self-predication and participation is more detailed and more novel than that. In his later metaphysics, Plato begins to assign to Forms a larger role in acting as unifying and structuring principles of one another and of sensibles. A more nuanced and fruitful interpretation of his Plural Predication approach will characterize the selfpredication and participation relations in more detail, and will help to clarify the explanatory role of Forms.

The particular Plural Predication approach I will defend is inspired by a proposal from Pelletier and Zalta (2000). On their view, the distinction

\footnotetext{
${ }^{28}$ A detailed version of this sort of Plural Predication approach has been developed by Connie Meinwald (1991). According to her, "The basic difference between such predications pros ta alla [...] and predications pros heauto is that predications pros heauto are not concerned with saying that individuals exhibit features. They have a role Plato regarded as more fundamental-namely, one of presenting the internal structures of the real natures [...] Thus 'Humanity has vertebrae' is a true predication pros heauto not in virtue of the fact that some abstract entity comes equipped with a backbone (there is no such fact) but because being vertebrate is part of what it is to be a human being" (Meinwald 1991, 71). Numerous challenges have been raised to Meinwald's proposals. For very different ways of reading the metaphysical revisions inspired by the Parmenides, see (Gill 2012), (Rickless 2007) and (Sayre 1983).
} 
between pros heauto and pros ta alla predication is the difference between encoding and exemplifying. In the case of sensibles, that would mean that the Form of $\mathrm{F}$ encodes $\mathrm{F}$ and a sensible exemplifies $\mathrm{F}$ in virtue of participating in the Form. ${ }^{29}$ Indeed, the only predication relation that sensibles can bear to their properties is an exemplification relation. As abstract objects, on the other hand, Forms can both exemplify properties (e.g. being intelligible) and encode properties. The properties they encode are those that are constitutive of their essences and that serve to individuate them. So, for example, the Form of Justice might encode 'each part of a complex whole does its own work and does not interfere with the other parts'. But, according to Pelletier and Zalta, the Form of Justice encodes more than that:

The Form of Justice is the ideal object that encodes all and only the properties entailed by the property of being just. Assuming that the property of being virtuous is entailed by the property of being just, this Form will encode the property of being virtuous as well as any other property entailed by the property of being just. (Pelletier and Zalta 2000, 177)

Forms encode those properties that constitute their essences or that are entailed by their essences. And sensibles exemplify all of the properties that are encoded in the Forms in which they participate.

To clarify, Plato does not take on all of the semantic and logical distinctions and elements in the multiple predicate approach developed by Pelletier and Zalta. ${ }^{30}$ They offer their proposal as a "friendly amendment" to developments in Plato's Parmenides and as a way of avoiding various paradoxes associated with abstract objects. But the proposal that Forms are ideal encoders is an extremely attractive one for making sense of paradigmatism and selfpredication in Plato. The proposal is so attractive that I would like to defend a Plural Predication approach that incorporates an encoding/exemplifying distinction.

Forms are abstract, intelligible objects in the later dialogues (Timaeus, Sophist, and Philebus) as well as in the middle ones. As abstract objects, they

${ }^{29}$ Slightly more technically: $y$ participates (pros ta alla) in $x$ if and only if there is a property $\mathrm{F}$ which is such that (a) $x$ is (identical to) the Form of $\mathrm{F}$ and (b) $y$ exemplifies F; and $y$ participates (pros heauto) in $x$ if and only if there is a property $\mathrm{F}$ which is such that: (a) $x$ is (identical to) the Form of F, and (b) F is part of the nature of $y$ (Pelletier and Zalta 2000, 175). On their account, the Form of F is distinct from the property being F. There are good reasons to draw the distinction, but a separate case would need to be made for thinking that Plato sees his way to drawing such a distinction.

${ }^{30}$ Zalta (1983) proposes the distinction between encoding and exemplifying in the course of developing an ontology of abstract objects. I do not, of course, intend to ascribe to Plato's multiple predication model all of the features of Zalta's model. But Zalta's terminology and some of his proposals are useful for understanding the Plural Predication approach I do wish to attribute to Plato. 
cannot exemplify all of the same properties that changing, material sensibles exemplify, though they can exemplify properties such as intelligibility and eternality. In addition, Forms are related to their essences in a nonexemplifying way. According to the Parmenides, Forms stand in a pros heauto predication relation to their essences. Essences are paradigms as objects of definition and knowledge, so it is reasonable to suppose that Forms are definable in virtue of the pros heauto relation they bear to their essences. Another way to put the point is to say that Forms are definable and knowable in virtue of encoding the properties that constitute their essences.

What evidence do we have that Forms encode essential properties? Aside from the advantages that come along with a proposal that works well for abstract objects of definition and knowledge, the evidence is drawn largely from Plato's examples. I see (at least) four trends that are well explained by a Plural Predication model according to which Forms stand in encoding relations to their essences and are, thereby, capable of standing in explanatory relations to the sensibles that participate in them. First, Plato is attracted to the idea that Forms are paradigms as functional ideals. Second, Plato seems preoccupied with structural ideals in the later dialogues. Third, Plato is increasingly inclined to explain the unity and order in sensibles by means of mathematical principles. Fourth, the appeal to Forms as encoding functional and mathematical structures makes good sense of Plato's fascination with the craftsman's reliance on Forms for guidance in organizing, unifying and producing sensible particulars. This last point is important, since it also provides some support for the idea that Forms can be metaphysically explanatory of sensibles in ways that go beyond merely classifying sensibles.

Forms encode functional structure already in the Cratylus and Republic where Plato discusses Forms for artifacts. In both cases, craftsmen look to the Forms for direction in producing sensible particulars that will serve certain purposes. ${ }^{31}$ In the Cratylus, the craftsman who makes a shuttle for weaving, looks to what a Shuttle itself is and puts into the artifact "the nature that best suits it to perform its own work" (Crat. 389b). The craftsman looks to the Form to understand how to build a tool capable of carrying out a certain function that will belong to the tool by nature. In Republic X, craftsmen look to Bed itself and Flute itself to produce sensibles with the structures required to serve certain purposes. The work of such craftsmen is supervised by the users of the products. The craftsmen strive to instantiate in sensible

${ }^{31}$ For discussion of Forms as functional ideals, see (Frede 1999, 2012). According to her, use (chreia) "determines what a good bed or a good flute should be like. Such a thought should have been quite germane to Aristotle's own point of view that a thing's essence lies in its function, but he seems to have been unaware of the possibility that this conception lies behind Plato's much vilified metaphor of 'participation"' (Frede 2012, 290-291). 
artifacts the structures encoded in the Forms in order to produce functionally suitable products for expert users. In these cases, although a craftsman brings something into existence as an efficient cause, what makes some particular sensible a shuttle or a bed or a flute is its structure and the functional capacities the structure brings to the artifact. Each artifact has a capacity to serve a certain purpose in virtue of the structure it exemplifies, a structure presumably encoded in the abstract Forms the craftsmen consult.

In the Sophist, Plato provides an insightful example of encoded and exemplified structure (Soph. 261c-263d). A piece of language, a string of words, is a well-formed sentence (logos) in virtue of each of its parts playing a particular functional role relative to the other parts and relative to the whole. ${ }^{32}$ 'Socrates learns' and 'Theaetetus sits' are both logoi in virtue of the function and organization of their parts. Both 'Socrates' and 'Theaetetus' are names (onomata); they function to indicate things that perform actions. 'Learns' and 'sits' are verbs (rhemata); they function to indicate actions. A logos is formed when a name is combined with a verb. Names do not combine with other names to form sentences. Verbs do not combine with other verbs. The Form of Logos itself encodes abstractly the particular organizational, functional structure that is exemplified in the sentences above. ${ }^{33}$ Those strings of words are logoi in virtue of exemplifying that structure.

Another cluster of examples illustrates Plato's developing inclination to characterize the organization and features of the sensible realm as the product of the mathematical structures realized in it. Among the most interesting and conspicuous examples of mathematical structure in Plato are those that occur in the Timaeus. I will mention only one type of example from the dialogue. When the craftsman of the cosmos looks to the Forms as models for creating the cosmic body, he creates the four material elements by imposing particular geometrical "forms and numbers" on the receptacle (Tim. 53b4-5). The Forms the craftsman consults apparently encode particular geometrical configurations to identify with each element: a cube for earth, an octahedron for air, a tetrahedron for fire, and an icosahedron for water. In these cases, Forms encode mathematical structures. They encode the mathematical ratios, proportions and geometrical configurations that structure the cosmos and the things in it. In the Timaeus sensibles have the natures and features they have in virtue of exemplifying those mathematical structures.

Certainly Aristotle is often inclined to cast Plato as an unapologetic

${ }^{32}$ For helpful discussion of this example, see (Harte 2006).

${ }^{33}$ Although she refrains from connecting her proposal to the idea that Forms encode essences by encoding structures, Verity Harte defends the view that abstract structures "turn out to be a basic and irreducible item in Plato's (late) ontology" (Harte 2006, 270). 
Pythagorean who proposes that Forms serve as mathematical causes of sensibles. Aristotle wonders if the proposal that Forms are numbers could mean that Callias is "a ratio, expressible in numbers, of fire, earth and water, then Human-itself, be it a certain kind of number or not, will nevertheless be a ratio, expressible in numbers, of certain things" (Met. I.9 991b9-21). Aristotle is critical of the proposal that Forms could be numbers or ratios and also causes, of course, but his remarks are useful in that they illustrate what the view that Forms encode mathematical structures might look like. And in fact, Plato proposes that animal bodies (including human bodies and the cosmic body) come into existence when divine intelligence sets the elements - earth, air, fire and water-in the proper harmonizing proportions (Tim. 53bff.; Phil. 28d5-30c7). Elsewhere, in the Philebus, examples of mathematical structure include musical harmonies, the seasons, and health, which is a mixture of the right ratios of the hotter and colder, and the wetter and drier (Phil. 25e7-8; for health, see also Rep. 444d).

A lot more could be said about how best to understand the view that the Form of $\mathrm{F}$ is pros heauto $\mathrm{F}$ by encoding mathematical properties or functional structures constitutive of F's essence. But the primary task of this paper is to gain insight into the nature of the participation relation, a pros ta alla relation. Since talk of the role paradigms play in the participation relation is the target of Aristotle's Emptiness Charge, I turn now to focus more exclusively on participation.

\section{Participation}

Enough has been said already to deflect Aristotle's Emptiness Charge. Forms are universal paradigms as ideal encoders of definable, structuring essences. The Form of F is self-predicative insofar as the Form of $\mathrm{F}$ encodes $\mathrm{F}$. We can understand the claim ' $x$ participates in F' to mean ' $x$ exemplifies the structure encoded in F.' So, for example, what all of the various healthy bodies have in common in participating in Health itself is simply exemplifying the appropriate ratios of hotter and colder, and wetter and dryer encoded in the Form of Health. Talk of paradigms and participation relations is not empty; rather, such talk has positive, significant content. Paradigms are abstract models that encode repeatable structures. Participation is a pros ta alla predication relation that relates a subject to something else: $x$ participates in $\mathrm{F}$ if and only if $x$ is $\mathrm{F}$ pros ta alla. $X$ is $\mathrm{F}$ pros ta alla if and only if $x$ exemplifies the structure encoded in the Form of F. In the case of sensibles, the structures a particular sensible exemplifies determine the nature and features of the sensible.

Consider an architectural design or blueprint or balsa wood model. The architect's visual model on the computer screen, sketch on blue paper, and 
wooden miniature are all quite different physical models or representations of abstract structure, the structure ultimately exemplified in a constructed house. In this case, the constructed house instantiates the design and structure represented physically in the architect's various models and encoded abstractly in the Form of House. House itself encodes the structure required for something to count as a house at all. The Form encodes information about the sorts of structures fit to carry out the function of a house; it encodes information about the necessary relations of parts to parts and parts to the whole to exemplify something that is sufficiently unified and organized to serve as a shelter. The constructed house is the physical exemplification of that abstract structure; its physical parts are organized and unified precisely to carry out the function of a house. The sensible house exemplifies the structure encoded in House itself.

Plato's proposed model of participation is sufficiently contentful to be distinguished from other models. The analysis of participation is clearly not the analysis of an imitation relation. ${ }^{34}$ And the results of the Parmenides ensure that a sensible $x$ does not exemplify $\mathrm{F}$ by instantiating imperfectly the very same property that a Form instantiates perfectly. $X$ does not exemplify $\mathrm{F}$ by being a copy of a perfect paradigmatic instance or by being deficiently similar to a Form. ${ }^{35}$ The Form-sensible exemplification relation is asymmetrical. A Form is a one over many in the sense that it encodes a single structure that can be exemplified many times in many different places, even in somewhat different ways. ${ }^{36}$ Although sensible instances of the structure will be symmetrically similar to one another, those instances will not bear that same similarity relation to the Form they exemplify.

Given some of the examples from Plato's corpus we have considered thus far, when $x$ participates in $\mathrm{F}$ by exemplifying $\mathrm{F}$, we can understand the participation relations along the following lines:

$X$ has the structure required to function as an F: This artifact is a flute.

$X$ realizes the structural organization of an F: This string of words

${ }^{34}$ Perhaps Plato must allow that, in some sense, structural isomorphism obtains between Forms and sensibles. But, if so, the kind of isomorphism at issue would not be a case of assimilation or resemblance as Aristotle and other commentators have understood it.

${ }^{35}$ And although we did not discuss this result from the Parmenides, neither does $x$ exemplify $\mathrm{F}$ by having a part or the whole of the Form in it (Parm. 131e5-7).

${ }^{36}$ In his discussion of the indeterminacy of Form properties as compared to the determinacy of sensible properties, Silverman notes that "here the model need not be another ship or shuttle or house at all. Indeed, the model-blueprint need not even specify particular material components, dimensions, sizes, weights or what have you, provided that the relevant ratios and proportions are maintained" (Silverman 2002, 330). 
is a logos.

$X$ is mathematically structured in accordance with F: This tetrahedron is an instance of fire.

In all three of Plato's cases, the sensible particulars are what they are and have the features and capacities they have in virtue, ultimately, of the structures they exemplify. It is reasonable to conclude that abstract Forms encode the metaphysical structure exemplified by their participant sensibles.

The craftsmanship evident in the examples is not accidental. In fact, it is important. The presence of an intelligent creative agent reminds us that the Forms are intelligible models that guide the agents as they introduce order and intelligibility into sensibles. And independently of the intelligent agent, the depiction of a craftsman consulting Forms also strongly suggests that Forms encode principles of composition, unity and structure. In order to build a sensible $\mathrm{F}$, one must build an $\mathrm{F}$ that satisfies the definition of $\mathrm{F}$ by exemplifying the structure of an F. A particular sensible counts as a flute because it can do what flutes do; and it can function as a flute in virtue of its compositional structure. The addition of compositional and functional structure as contained in the essence encoded in a Form adds to the explanatory power of the Plural Predication model. For it is not just that a sensible F satisfies the definition of $\mathrm{F}$ itself and, so, can be classified as an F. It is not just that the concepts articulated in the definition hold true of the sensible. In addition, the sensible that exemplifies the structure encoded in $\mathrm{F}$ has its unity, organization and function fixed by its structure. The addition of structure to the model allows us to assign a metaphysically richer role to Forms than is available in earlier Plural Predication models.

Appeals to craftsmanship provide vivid illustrations of the added explanatory power of Forms that encode essential structure. But, strictly speaking, an intelligent agent would not be required (though Plato might think otherwise). Consider the case of the human eye. Let us suppose that the eye is an organ for seeing, that what it is to be an eye is to be an organ for sight. If there were a Form of Eye itself, it would encode the information that an eye is an organ of sight. But the Form of Eye itself would also encode the suitable type, structure and organization of the matter that is required of anything that is to count as an organ of sight. And the Form would be metaphysically explanatory of sensible eyes insofar as its definition both classifies the sensible eyes and also provides compositional principles for the sensibles so classified. Forms count as aitia, then, in that they metaphysically explain how their sensible instances have the organization, structure, features, capacities and functions they have. The Form of F makes $x$ to be an F not simply in virtue of $x$ satisfying the definition of $\mathrm{F}$. $X$ must also exemplify 
the structure encoded in $\mathrm{F}$, where that requirement extends to how the parts and wholes of $x$ are arranged and how $x$ 's various parts are (mathematically) configured to carry out certain functions, namely the function of an F.

The idea that Forms encode structures is especially appealing to Plato when he considers artifact kinds and natural kinds. But apparently he sees no obvious distinction between Forms that encode kinds and Forms that encode monadic or relational properties (much to Aristotle's dismay). Poppy is both human and healthy in virtue of the same predication relations. She participates in Forms. She exemplifies the mathematical structures encoded in both Human itself and Health itself. Poppy is human if, among other things, her body exemplifies harmonizing proportions of earth, air, fire and water. Poppy is healthy if the material elements of her body exemplify the right ratio of hotter to colder and wetter to dryer.

\section{Metaphysical Explanation}

For both Plato and Aristotle, the entities that play a role in metaphysical explanation must be ontologically prior to the entities that they play a role in explaining. For Aristotle, metaphysical explanations of sensible particulars and their features require appeals to substantial forms as primary causal principles that actualize potentialities in matter (or material compounds) and give rise to the various potentialities that the consequent hylomorphic compounds will have. Aristotle adds that substantial forms are causally prior to and in sensibles. For Plato, metaphysical explanations of sensible particulars require appeals to abstract Forms that are the aitia of sensibles insofar as those Forms encode the structures that their participant sensibles exemplify. For Plato, metaphysical explanations require that what makes $\mathrm{F}$ things to be $\mathrm{F}$ must itself be $\mathrm{F}$ and never not F. Forms that encode structures satisfy the constraint on a Plural Predication model. ${ }^{37}$ The Form of F is F pros heauto, in virtue of encoding $\mathrm{F}$; it never encodes not $\mathrm{F}$.

Plato's Forms are his basic beings. If they are ontologically prior to sensibles, if exemplifying the structure encoded in the Form of $\mathrm{F}$ is what makes a sensible an instance of $\mathrm{F}$, and if grasping definitions of Forms is what provides understanding of the natures and features in sensibles, then Forms are very plausibly regarded as metaphysically explanatory of sensibles. The Plural Predication model outlined thus far takes Forms to be universal, definable, abstract, encoders of essence and structure. Sensibles that participate in such Forms by exemplifying the encoded structures are both classified as instances of the essences and unified by the structures they exemplify. What

${ }^{37}$ What makes Poppy healthy is the fact that her body's elements stand in the right ratios of hotter to wetter and colder to dryer, the ratios encoded in the Form of Health. 
remains, then, in order to round out the discussion of metaphysical explanation, is a more general accounting of ontological priority in Plato.

Although the details of various independence and dependence relations in Plato's ontology require more attention than we can give to them here, there are two elements of those relations that it will be useful to clarify, even if only briefly: ontological separation and ontological priority (and its correlate ontological dependence). Aristotle attributes a view of ontological priority to Plato. According to Aristotle, "something is prior in respect of its nature and substance, when it is possible for it to be (einai) without other things, but not the latter without it; this division was used by Plato" (Met. V.11 1019a2-4).$^{38}$ If Aristotle is correct, Plato understands ontological priority in the following way: $x$ is ontologically prior to $y$, if $x$ can be without $y$, but $y$ cannot be without $x$. Forms are Plato's basic beings and are his candidates for being ontologically prior to sensibles. Forms are ontologically separate from sensibles if they can be independently of sensibles. Forms are ontologically prior to sensibles if the relation is asymmetric, if Forms can be independently of sensibles, but sensibles cannot be independently of Forms.

But what does it mean for Forms and sensibles "to be?" Although Plato is often interpreted as identifying ontological priority with priority in existence, ${ }^{39}$ his ontology and his dialogues support a broader construal of the relation of ontological priority. In this case, the broader construal is also a more textually conservative one, since it honors more of the various ways in which the phrase 'to be' might be used by Plato and Aristotle. ${ }^{40}$ I propose that we understand the phrase 'to be' to stand for something like 'to have the ontological status or profile it has'. There is some evidence that Aristotle himself understood ontological priority in this way, and, so, there is some evidence that Plato did too (since Aristotle borrows a formula for

${ }^{38}$ See also Eudemian Ethics 1217b2-15.

${ }^{39}$ See, for example, (Fine 1984) and (Peramatzis 2011).

${ }^{40}$ What exactly ontological priority consists in for Plato and Aristotle is a somewhat vexed question. My own view is that Plato recognizes forms of ontological priority that include but go beyond priority in existence. To be sure, the Form of Beauty can exist even if there are no beautiful sensibles; but beautiful sensibles cannot exist without the Form of Beauty itself. So the Form of Beauty is ontologically prior in existence to beautiful sensibles. But Forms are also ontologically prior in being to sensibles. The Form of Beauty can be what it is to be beautiful and encode beauty without sensibles exemplifying beauty, but sensibles cannot exemplify beauty without the Form of Beauty being what it is to be beautiful and encoding beauty. For Plato, sensibles that come-to-be F depend for their Fness on standing in participation relations to Forms that just are what it is to be F and encode F. But the Form of $\mathrm{F}$ is not what it is to be $\mathrm{F}$ and an encoder of $\mathrm{F}$ in virtue of the sensibles that come-to-be F. Forms are ontologically prior to sensibles in both existence and being. For distinct treatments of ontological priority relations in Plato and Aristotle, see (Beere 2009), (Corkum 2008), (Fine 1984), and (Peramatzis 2011). 
ontological priority that he attributes to Plato) ${ }^{41}$ In that case, Forms are ontologically prior to sensibles if they can have the ontological status they have independently of sensibles, but sensibles cannot have the ontological status they have independently of Forms. Given the argument of this paper, ontological priority of the Forms would consist in the following: The Form of $\mathrm{F}$ can exist, can be what it is to be F, and can encode F independently of sensibles existing and exemplifying $\mathrm{F}$, but sensibles cannot exist and exemplify $\mathrm{F}$ independently of a Form existing, being what it is to be $\mathrm{F}$ and encoding F. Forms can exist and have the ontological status they have even if uninstantiated (as the Timaeus indicates). Sensibles, on the other hand, cannot exist or exemplify structures or have features in the absence of corresponding Forms. Forms are ontologically prior to sensibles, then, and sensibles are ontologically dependent on Forms.

Plato's Forms and their relations to sensibles meet the conditions (broadly construed) that he places on metaphysical explanations. By Plato's lights, Forms as abstract encoders of structures are definable essences that classify, unify and are ontologically prior to the sensibles that participate in them. As Plato's ontology develops, so do his resources for defending a model of metaphysical explanation that competes with Aristotle's. When Forms encode the structures exemplified in sensibles, Plato regards the relation as a case of metaphysical determination that is not efficient or event causation. ${ }^{42}$ If he is right, then Forms are metaphysically explanatory of sensibles. And, although a more detailed account of the metaphysics of encoding, of exemplifying and of sensible particulars is required in order to determine just how well Plato's proposals compete with Aristotle's, that his proposals are competitive is an idea worth taking seriously.

Plato defends the view that Forms are substances and principles of sensibles insofar as they encode structural essences and insofar as sensibles exemplify those structures. Like Aristotle's substantial forms, Plato's Forms are not elements or parts of the sensible structures they explain. ${ }^{43}$ Indeed (if

${ }^{41}$ This sort of approach to understanding Aristotle's view of ontological independence is adopted and defended by Corkum (2008). It seems to me that this kind of approach makes sense for both Plato and Aristotle.

${ }^{42}$ Contemporary accounts of grounding often find inspiration in Plato and Aristotle for a special kind of metaphysical explanation. Grounding is described as "a distinctive kind of metaphysical explanation, in which explanans and explanandum are connected, not through some sort of causal mechanism, but through some constitutive form of determination" (Fine 2012, 37). For some discussion of grounding in Plato, and especially in the Euthyphro, see (Evans 2012) and (Wolfsdorf 2005).

${ }^{43}$ For discussion of the ontological status of Platonic structures, see (Harte 2006). Koslicki (2008) also discusses structure in Plato and Aristotle, in addition to defending her own view of the role of structure in composition. Unlike Plato and Aristotle, Koslicki includes structures as parts of wholes. 
Aristotle is correct), Plato's Forms are not in sensibles at all. Rather, Forms are supposed to serve as unifying, organizing, structuring and classifying principles of material particulars without being present in them. And it is at this point in the dialectic with Aristotle, that Plato needs to address The Separation Charge if his metaphysics is to remain viable and competitive.

\section{Conclusion}

Aristotle is right to be confused about how exactly assimilation is possible between a separate, abstract Form and a physical entity, or how similarity between the two would count as metaphysically explanatory. ${ }^{44}$ But Aristothe is wrong to think that Plato's appeals to participation are mere metaphor or empty talk. Plato's language and attention are sometimes aimed at assimilation relations and sometimes at exemplification relations. At different points, Plato has reasons for pursuing the idea that Forms as aitia have the very same features they produce in their participant sensibles. So, at some points in the middle dialogues, he treats Forms as self-exemplifying and participation as similarity. But eventually Plato rejects Assimilation models of participation and endorses a Plural Predication model, a model he has also been interested in all along. Eventually, Plato comes to endorse a Plural Predication model according to which Forms encode F, sensibles exemplify F, and Forms are the classifying and structuring principles of their participant sensibles. Had Aristotle treated the Parmenides, Sophist, Timaeus and Philebus sympathetically and at more length than the Phaedo, he might have found less to complain about in Plato's metaphysics. At the very least, he might have been less interested in levelling The Emptiness Charge.

Even so, Aristotle is right that Plato does not have a clear, well-developed, or well-defended account of the metaphysics of sensible particulars. ${ }^{45}$ And Aristotle is right that in order to make progress in assessing the plausibility of Plato's metaphysics, an investigation of The Separation Charge is called for. Still, if we help ourselves to the proposal that a Form is an ideal, abstract encoder of structure, and a sensible participates in a Form by exemplifying what is encoded in the Form, we have something contentful to say on Plato's behalf about participation. Talk of exemplifying structure is not empty or idle talk. If it makes sense to talk of a particular house exemplifying the structure represented in a two-dimensional architectural blueprint, then it makes sense to talk of a house exemplifying the structure encoded in an ab-

${ }^{44}$ Aristotle complains that similarity could be accidental; the relation all by itself is not sufficient to count as explanatory (Met. 991a23-27).

${ }^{45}$ That is not to say that Plato has nothing to say about the metaphysics of sensibles. In the Timaeus and Philebus Plato makes significant progress toward developing a metaphysics of sensible particulars. 
stract model. At least talk of one kind of object containing a structure that is exemplified in another kind of object where the first is not the efficient or event cause of the second makes sense. ${ }^{46}$

One thing is certain. Although Plato and Aristotle might end up with roughly analogous proposals about the sorts of roles that primary causes play in metaphysical explanation, their favored candidates for occupying the role of primary substance are very different. Aristotle prefers to think of formal causes as natural principles in and of changing, natural bodies. Plato finds his inspiration in mathematics and looks to separate, abstract structures to ground his ontology. Indeed, one of Aristotle's most consistent charges against Plato and the Platonists is perhaps spot on, that "mathematics has come to be philosophy for people nowadays" (Met. 992a29-b1).

\section{Bibliography}

Allen, R. E. (1960). Participation and predication in Plato's middle dialogues, The Philosophical Review 69: 147-164.

Beere, J. (2009). Doing and Being: An Interpretation of Aristotle's Metaphysics Theta, Oxford University Press, Oxford.

Bolton, R. (1998). Plato's discovery of metaphysics: The new Methodos of the Phaedo, in J. Gentzler (ed.), Method In Ancient Philosophy, Oxford University Press, Oxford, pp. 91-111.

Code, A. (1983). On the origins of some Aristotelian theses about predication, in J. Bogen and J. McGuire (eds), How Things Are, D. Reidel, Dordrecht, pp. 101-133.

Corkum, P. (2008). Ontological dependence in Aristotle, Phronesis 58: 6592.

Devereux, D. (1994). Separation and immanence in Plato's theory of Forms, Oxford Studies in Ancient Philosophy 12: 63-90.

Devereux, D. (2003). Plato: Metaphysics, in C. Shields (ed.), The Blackwell Guide to Ancient Philosophy, Blackwell Publishing Ltd, Oxford, pp. 75-99.

Evans, M. (2012). Lessons from Euthyphro 10a-11b, Oxford Studies in Ancient Philosophy 42: 1-38.

${ }^{46}$ Whether or not abstract entities can in fact encode structures and whether or not sensibles can actually be related to separate Forms are different and perhaps more challenging questions. 
Ferejohn, M. (2013). Formal Causes: Definition, Explanation and Primacy in Socratic and Aristotelian Thought, Oxford University Press, Oxford.

Fine, G. (1984). Separation, Oxford Studies in Ancient Philosophy 2: 31-87.

Fine, G. (1986). Immanence, Oxford Studies in Ancient Philosophy 4: 71-97.

Fine, G. (1993). On Ideas, Clarendon Press, Oxford.

Fine, K. (2012). Guide to ground, in F. Correia and B. Schneider (eds), Metaphysical Grounding: Understanding the Structure of Reality, Cambridge University Press, Cambridge, pp. 37-80.

Frede, D. (1999). Plato on what the body's eye tells the mind's eye, Proceedings of the Aristotelian Society 99: 191-209.

Frede, D. (2012). The doctrine of Forms under critique: Part I, in C. Steel and O. Primavesi (eds), Aristotle's Metaphysics Alpha, Oxford University Press, Oxford, pp. 265-296.

Frede, M. (1967). Prädikation und Existenzaussage, Vol. 18 of Hypomnemata, Vandenhoeck und Ruprecht, Göttingen.

Frede, M. (1992). The Sophist on false statements, in R. Kraut (ed.), The Cambridge Companion to Plato, Cambridge University Press, Cambridge, pp. 397-424.

Gill, M. L. (2012). Philosophos: Plato's Missing Dialogue, Oxford University Press, Oxford.

Harte, V. (2006). Plato on Parts and Wholes: The Metaphysics of Structure, Oxford University Press, Oxford.

Koslicki, K. (2008). The Structure of Objects, Oxford University Press, Oxford.

Malcolm, J. (1991). Plato on the Self-Predication of Forms, Oxford University Press, Oxford.

McCabe, M. M. (1994). Plato's Individuals, Princeton University Press, Princeton.

Meinwald, C. (1991). Plato's Parmenides, Oxford University Press, New York.

Meinwald, C. (1992). Good-bye to the third man, in R. Kraut (ed.), The Cambridge Companion to Plato, Cambridge University Press, Cambridge, pp. 365-396.

Nehamas, A. (1979). Self-predication and Plato's theory of Forms, American Philosophical Quarterly 16: 93-103.

Pelletier, F. and Zalta, E. (200o). How to say goodbye to the third man*, Noûs 34: 165-202. 
Peramatzis, M. (2011). Priority in Aristotle's Metaphysics, Oxford University Press, Oxford.

Peterson, S. (1996). Plato's Parmenides: A principle of interpretation and seven arguments, Journal of the History of Philosophy 34: 167-192.

Prior, W. (1983). The concept of paradeigma in Plato's theory of Forms, Apeiron: A Journal for Ancient Philosophy and Science 17: 33-42.

Rickless, S. (2007). Plato's Forms in Transition: A Reading of the Parmenides, Cambridge University Press, New York.

Sayre, K. (1983). Plato's Late Ontology, Princeton University Press, Princeton.

Schofield, M. (1996). Likeness and likenesses in the Parmenides, in C. Gill and M. M. McCabe (eds), Form and Argument in Late Plato, Clarendon Press, Oxford, pp. 79-103.

Sharma, R. (2009). Socrates' new Aitia: Causal and metaphysical explanations in plato's Phaedo, Oxford Studies in Ancient Philosophy 36: 137-177.

Shields, C. (2008). Plato and Aristotle in the academy, in G. Fine (ed.), The Oxford Handbook of Plato, Oxford University Press, New York, pp. 504525 .

Silverman, A. (2002). The Dialectic of Essence, Princeton University Press, Princeton.

Steel, C. and Primavesi, O. (2012). Aristotle’s Metaphysics Alpha: Symposium Aristotelicum, Oxford University Press, Oxford.

Stough, C. (1979). Forms and explanations in the Phaedo, Phronesis 21: 1-30.

Thomas, C. J. (n.d.). Plato on separation and participation. Unpublished manuscript.

Vlastos, G. (1969a). Plato's third man argument (Parm.132a1-b2): Text and logic, Philosophical Quarterly 19: 289-301.

Vlastos, G. (1969b). Reasons and causes in the Phaedo, The Philosophical Review 78: 291-325.

Wolfsdorf, D. (2005). Euthyphro 10a2-bi1b1: A study in Platonic metaphysics and its reception since 1960, Apeiron: A Journal for Ancient Philosophy and Science 38: 1-71.

Zalta, E. (1983). Abstract Objects: An Introduction to Axiomatic Metaphysics, Reidel Publishing Company, Dordrecht. 